УДК 681.513 .5

\title{
MODELING OF OPTIMAL AUTOMATIC CONTROL OF THE PROCESS OF BIOLOGICAL CLEARING OF POLLUTED WATERS BY FROZEN ORDER REGULATORS
}

\author{
O. Lobok, B. Goncharenko, M. Sych \\ National University of Food Technologies
}

\begin{tabular}{|c|c|}
\hline & \multirow{12}{*}{$\begin{array}{l}\text { The problem of modeling the control of the process of } \\
\text { biological treatment of polluted water using fractional regu- } \\
\text { lators is considered and solved in the paper. Mathematical } \\
\text { modeling of the biological purification process as a control } \\
\text { object is considered, a linear dynamic control model is } \\
\text { obtained. The criterion of the quality of automatic control of } \\
\text { a fractional regulator by the functioning of a biological } \\
\text { water purification system has been introduced. Optimum } \\
\text { tunings of fractional regulators are obtained, the dynamics } \\
\text { of transient processes of control action and the state of the } \\
\text { purification system is investigated. Numerical simulation of } \\
\text { fractional and classical control is carried out, a higher } \\
\text { efficiency of fractional regulators is shown. }\end{array}$} \\
\hline Fractional & \\
\hline Differentint & \\
\hline Opti & \\
\hline Numerical & \\
\hline$n$ of $w$ & \\
\hline & \\
\hline Received 19.11.2017 & \\
\hline Received in revised fo & \\
\hline & \\
\hline Accepted & \\
\hline $\begin{array}{l}\text { Corresponding auth } \\
\text { O. Lobok }\end{array}$ & \\
\hline
\end{tabular}

DOI: $10.24263 / 2225-2924-2017-23-6-5$

\section{МОДЕЛЮВАННЯ ОПТИМАЛЬНОГО АВТОМАТИЧНОГО КЕРУВАННЯ ПРОЦЕСОМ БІОЛОГІЧНОЇ ОЧИСТКИ ЗАБРУДНЕНИХ ВОД РЕГУЛЯТОРАМИ ДРОБОВОГО ПОРЯДКУ}

\author{
О.П. Лобок, Б.М. Гончаренко, М.А. Сич \\ Національний університет харчових технологій
}

У статті розглядається $i$ вирішується завдання чисельного моделювання щзодо керування прочесом біологічної очистки забруднених вод за допомогою дробових $P I^{\lambda} D^{\mu}$-регуляторів. Отримано оптимальні налаштування дробових регуляторів, досліджено динаміку перехідних процесів керувального впливу $і$ вихідного показника стану очисної системи. Проведено чисельне моделювання керування дробовими $P I^{\lambda} D^{\mu}$-регулятором $i$ класичним PIDрегулятором, показана висока ефективність дробових регуляторів.

Ключові слова: дробове числення, диферінтегратор, оптимальне керування, чисельне моделювання, біоочищення вод. 
Поставка проблеми. Дробове числення має справу з похідними та інтегралами довільного порядку (раціонального, дійсного і навіть комплексного). Дробовим численням в XVII ст. займалися Ріман, Лиувіль, Грюнвальд, Літник $[4 ; 5 ; 8]$. Але особливо активно розвивається теорія дробового числення в останні роки, і результати іï широко використовуються при дослідженні хаотичної динаміки, динамічних нейронних мереж 3 дробовими порядками, конструюванні (синтезу) регуляторів дробових порядків у теорії автоматичного керування тощо.

Оператором, що узагальнює класичні диференційний та інтегральний оператори, називається оператор виду

$$
{ }_{a} D_{t}^{\gamma}= \begin{cases}d^{\gamma} / d t^{\gamma}, & \gamma>0 \\ 1, & \gamma=0, \\ \int_{a}^{t}(d \tau)^{-\gamma}, & \gamma<0\end{cases}
$$

де $\gamma$ - дробовий порядок оператора (дійсне число); $a$ - постійна, пов'язана 3 початковими умовами динамічного процесу.

Оператор (1) часто називають диферінтегратором, оскільки він об'єднує в собі відразу два поняття - похідної та інтеграла.

Традиційно теорія і практика автоматичного керування орієнтовані на застосування класичного диференціального або інтегрального числення, що $€$ цілком логічним, однак з розвитком дробового числення виникає потреба дослідження можливостей застосування дробових законів керування та побудови дробових регуляторів і виявлення особливостей систем керування з ними.

Метою статті $\epsilon$ не тільки порівняння дробових регуляторів 3 класичними та вивчення можливості й ефективності застосування їх у системах автоматичного керування, але й чисельне моделювання процесів керування очищенням забруднених вод.

Викладення основних результатів дослідження. У пропонованому дослідженні розглянуто задачу чисельного моделювання керування процесом біологічної очистки стічних вод активним мулом з використанням $P I^{\lambda} D^{\mu}$ регуляторів дробового порядку. Очисна система (рис. 1) складається 3 біореактора-аеротенка і відстійника мулу.

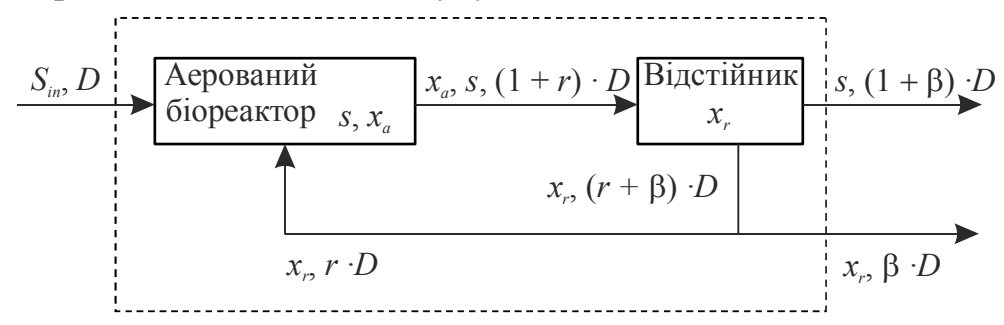

Рис. 1. Схема процесу очищення стічних вод

Математична модель, що описує очищення води за даною схемою, отримана на основі матеріального балансу для аератора і відстійника у вигляді такої системи диференціальних рівнянь: 


$$
\left\{\begin{array}{l}
\frac{d x_{a}(t)}{d t}=\mu(t) x_{a}(t)-D(t)(1+r) x_{a}(t)+r D(t) x_{r}(t) \\
\frac{d s(t)}{d t}=-\frac{\mu(t)}{Y} x_{a}(t)-D(t)(1+r) s(t)+D(t) s_{i n}(t), \\
\frac{d x_{r}(t)}{d t}=-D(t)(\beta+r) x_{r}(t)+D(t)(1+r) x_{a}(t)
\end{array}\right.
$$

де $x_{a}(t), s(t)$ - відповідно, концентрація біомаси і субстрату в біореакторі; $x_{r}(t)$ - концентрація рециркуляційної біомаси; $D(t)$ - ступінь розведення, який визначається як $D(t)=F(t) / V$, де $F(t)$ - об'ємна швидкість потоку, $V$ - обсяг біореактора; $s_{i n}(t)$ - концентрація субстрату у вхідному потоці; $Y$ - фактор виходу (прибутковості) біомаси; $\mu(t)$ - питома швидкість росту біомаси, яка визначається за формулою Моно [3]:

$$
\mu(t)=\mu_{\max } \frac{s(t)}{k_{s}+s(t)},
$$

де $\mu_{\max }$ - максимальна питома швидкість росту біомаси; $k_{s}$ - константа насичення, що визначається експериментальним шляхом; $r, \beta-$ коефіцієнти, що визначають, відповідно, відношення рециркуляційного потоку і потоку відходів біомаси до вхідного потоку; $x_{a 0}, s_{0}, x_{r 0}$ - відповідно, концентрація біомаси, субстрату і рециркуляційної біомаси в початковий момент часу $t_{0}$; $t_{0}<t \leq T, T-$ кінцевий момент часу керування процесом.

Як регульований параметр (вихід моделі) виберемо величину $s(t)-$ концентрацію субстрату в біореакторі, яка визначає якість очищення води. Як керувальний вплив (дію) на систему виберемо функцію ступінь розведення $D(t)$.

Для зручності систему (2) запишемо у векторному вигляді:

$$
\left\{\begin{array}{l}
\frac{d x(t)}{d t}=f(x(t), u(t)), \quad t_{0}<t \leq T, \\
x\left(t_{0}\right)=x^{0}
\end{array}\right.
$$

де

$$
\begin{gathered}
f(x(t), u(t))=\left(\begin{array}{l}
f_{1}(x(t), u(t)) \\
f_{2}(x(t), u(t)) \\
f_{3}(x(t), u(t))
\end{array}\right), x(t)=\left(\begin{array}{l}
x_{1}(t) \\
x_{2}(t) \\
x_{3}(t)
\end{array}\right)=\left(\begin{array}{c}
x_{a}(t) \\
s(t) \\
x_{r}(t)
\end{array}\right), u(t)=D(t), \\
f_{1}(x(t), u(t))=\mu(x(t)) x_{1}(t)-(1+r) x_{1}(t) u(t)+r x_{3}(t) u(t), \\
f_{2}(x(t), u(t))=-\frac{\mu(x(t))}{Y} x_{1}(t)-(1+r) x_{2}(t) u(t)+s_{i n}(t) u(t), \\
f_{3}(x(t), u(t))=-(\beta+r) x_{3}(t) u(t)+(1+r) x_{1}(t) u(t),
\end{gathered}
$$




$$
\mu(x(t))=\mu_{\max } \frac{x_{2}(t)}{k_{s}+x_{2}(t)} .
$$

Регульований параметр при цьому можна записати так:

$$
s(t)=x_{2}(t)=c^{T} x(t)
$$

де $c=\left(\begin{array}{lll}0 & 1 & 0\end{array}\right)^{T}$.

Лінеарізуємо перетворену систему (4) в околі заданого номінального керування $u^{*}$ і відповідного йому вектора рівноважного стану $x^{*}=\left(x_{1}^{*}, x_{2}^{*}, x_{3}^{*}\right)^{T}$, при якому $f\left(x^{*}, u^{*}\right)=0$, і який визначається як розв'язок системи нелінійних рівнянь $f\left(x, u^{*}\right)=0$ щодо вектора $x$.

Введемо позначення:

$$
\Delta x(t)=\left(\begin{array}{l}
\Delta x_{1}(t) \\
\Delta x_{2}(t) \\
\Delta x_{3}(t)
\end{array}\right)=\left(\begin{array}{c}
x_{1}(t)-x_{1}^{*} \\
x_{2}(t)-x_{2}^{*} \\
x_{3}(t)-x_{3}^{*}
\end{array}\right)=x(t)-x^{*}, \Delta u(t)=u(t)-u^{*} .
$$

Тоді лінеаризовану систему рівнянь моделі (4) можна представити у такому вигляді:

$$
\left\{\begin{array}{l}
\frac{d \Delta x(t)}{d t}=A \Delta x(t)+b \Delta u(t) \\
\Delta x\left(t_{0}\right)=x^{0}-x^{*}
\end{array} .\right.
$$

3 огляду на співвідношення (6) і позначення (7) рівняння для регульованої змінної (вихід моделі) запишеться у вигляді:

$$
\Delta s(t)=c^{T} \Delta x(t)
$$

де $\Delta s(t)=s(t)-c^{T} x^{*}$.

Модель керування (8) має один вхід і один вихід. Відомим способом стабілізації потрібних параметрів $є$ застосування регуляторів у зворотному зв'язку в складі контура автоматизованої системи керування. Використаємо дробовий $P I^{\lambda} D^{\mu}$-регулятор $[1 ; 2]$ і порівняємо його ефективність 3 класичним $P I D$-регулятором.

Аналогічно [7; 9] $P I^{\lambda} D^{\mu}$-регулятори представимо у вигляді:

$$
\Delta u(t)=k_{P}(\Delta s(t))+k_{I}\left({ }_{t_{0}} D_{t}^{-\lambda} \Delta s(t)\right)+k_{D}\left({ }_{t_{0}} D_{t}^{\mu} \Delta s(t)\right),
$$

де $k_{P}, k_{I}, k_{D}$ - налагоджувальні коефіцієнти регулятора; ${ }_{t_{0}} D_{t}^{-\lambda} \Delta s(t)-$ дробова похідна порядку $\lambda ;{ }_{t} D_{t}^{\mu} \Delta s(t)$ - дробовий інтеграл порядку $\mu$, причому $\lambda, \mu$ - довільні дійсні числа 3 інтервалу $(0,2)$, тобто $\lambda, \mu \in(0,2)$. Якщо $\lambda \geq 2$ або $\mu \geq 2$, то $P I^{\lambda} D^{\mu}$-регулятор набуває високого порядку, $\mathrm{i}$ структура його відрізняється від класичного PID-регулятора. Регулятор (10) є узагальненим дробовим $P I D$-регулятором. При $\lambda=1$ i $\mu=1$ маємо класичний 
$P I D$-регулятор, якщо $\lambda=1, \mu=0$, то отримуємо $P I$-регулятор, при $\lambda=0, \mu=1$ маємо $P D$-регулятор і при $\lambda=0, \mu=0-P$-регулятор. Всі ці різновиди класичних $P I D$-регуляторів $\epsilon$ окремими випадками дробового $P I^{\lambda} D^{\mu}$ регулятора (10). Однак $P I^{\lambda} D^{\mu}$-регулятор є більш гнучким і має можливість краще регулювати (налаштовувати) динамічні властивості систем керування. На $P-I-D$-площині це означає, що замість «стрибків» між чотирма фіксованими точками (P, PI, PD $i$ PID (рис. 2)) на площині є можливість неперервного пересування $\left(P I^{\lambda} D^{\mu}\right)$ між ними.

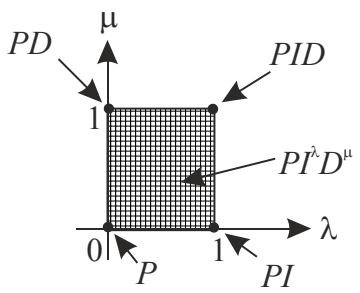

Рис. 2. $P$ - I - D -площина дробових порядків похідних та інтегралів

Дробові похідні та інтеграли визначаються як межа

$$
{ }_{t_{0}} D_{t}^{\alpha} f(t)=\lim _{h \rightarrow 0} h^{-\alpha} \sum_{j=0}^{\left[\frac{t-t_{0}}{h}\right]}(-1)^{j}\left(\begin{array}{c}
\alpha \\
j
\end{array}\right) f(t-j h)
$$

де $\left(\begin{array}{l}\alpha \\ j\end{array}\right)$ - біноміальні коефіцієнти вигляду $\left(\begin{array}{c}\alpha \\ j\end{array}\right)=\frac{\Gamma(\alpha+1)}{\Gamma(j+1) \cdot \Gamma(\alpha-j+1)}$, в яких $\Gamma(x)$ - гама-функція Ейлера вигляду $\Gamma(x)=\int_{0}^{+\infty} e^{-y} y^{x-1} d y$ (нагадаємо, що при цілому $x=k$ вона дорівнює $\Gamma(k+1)=k !) ;[\cdot]$ — ціла частина числа; $h>0$ приріст часової координати (квантування).

Якщо $\alpha>0$, то формула (11) визначає дробову похідну, якщо ж $\alpha<0$, то дробовий інтеграл. Тому співвідношення (11) часто називають диферінтегратором, як і співвідношення (1). Відзначимо також, що при цілих порядках $\alpha$ в (11) буде кінцева сумма, а при дробових $\alpha$ - нескінченне число членів ряду.

3 урахуванням (9), $P I^{\lambda} D^{\mu}$-регулятор (10) запишемо у вигляді оператора від стану $\Delta x(t)$ :

$$
\Delta u(t)=c^{T}\left(k_{P}(\Delta x(t))+k_{I}\left({ }_{t_{0}} D_{t}^{-\lambda} \Delta x(t)\right)+k_{D}\left({ }_{t_{0}} D_{t}^{\mu} \Delta x(t)\right)\right),
$$

а критерій якості автоматичного керування функціонуванням системи біологічної очистки як:

$$
J_{p}=\int_{t_{0}}^{T}|\Delta s(t)|^{p} d t=\int_{t_{0}}^{T}\left|c^{T} \Delta x(t)\right|^{p} d t
$$

де $p>0$ - параметр, який на практиці приймають рівним $p=1$ (модуль похибки) або $p=2$ (середньоквадратична похибка). 
Для чисельної реалізації сформульованої задачі оптимального регулювання дискретизуємо систему (8), дробовий $P I^{\lambda} D^{\mu}$-регулятор (12) і критерій (13), розбивши часовий інтервал $\left[t_{0}, T\right]$ на $n$ частин $з$ кроком $h=\left(T-t_{0}\right) / n$ ( $h$ - період квантування). Точки розбиття в $\left[t_{0}, T\right]$ позначимо через $t_{k}$, а стан системи (8) в ці моменти часу $t_{k}$ - через $z_{k}=\Delta x\left(t_{k}\right)$.

Апроксимуємо неперервний вхідний сигнал $\Delta u(t)$ кусково постійною функцією: $\Delta u(t)=u_{k}$ при $t_{k} \leq t<t_{k+1}, k=0,1,2, \ldots, n$ i, використовуючи матрицю лінійної неперервної системи (8), отримаємо такий іï дискретний аналог:

$$
\left\{\begin{array}{l}
z_{k+1}=e^{A h} z_{k}+A^{-1}\left(E-e^{-A h}\right) b u_{k}, \quad k=0,1,2, \ldots, n-1, \\
z_{0}=x^{0}-x^{*}
\end{array}\right.
$$

де $E$ - одинична матриця; $e^{A h}-$ матрична експонента.

Далі дискретний дробовий $P I^{\lambda} D^{\mu}$-регулятор представимо у вигляді:

$$
u_{k}=c^{T}\left(k_{P}\left(z_{k}\right)+k_{I}\left(h^{\lambda} \sum_{j=0}^{k} w_{j}^{(-\lambda)} z_{k-j}\right)+k_{D}\left(h^{-\mu} \sum_{j=0}^{k} w_{j}^{(\mu)} z_{k-j}\right)\right) .
$$

Відмітимо, що при $k=0$ керувальний сигнал дорівнює:

$$
u_{0}=\left(k_{P}+k_{I} h^{\lambda}+k_{D} h^{-\mu}\right) c^{T} z_{0} .
$$

Критерій якості (13) запишемо в дискретизованому вигляді:

$$
J_{p}=\frac{h}{2}\left(\left|c^{T} z_{0}\right|^{p}+2 \sum_{j=1}^{n-1}\left|c^{T} z_{j}\right|^{p}+\left|c^{T} z_{n}\right|^{p}\right) .
$$

Чисельне моделювання керованої системи біоочищення і пошук оптимального регулятора здійснювалися при таких вихідних даних: $s_{i n}=200$ [мг/Л], $Y=0,65, \mu_{\max }=0,15$ [год $^{-1}$ ] $k_{s}=100$ [мг/л], $r=0,6, \beta=0,2, u^{*}=0,05$ [год $^{-1}$ ], $t_{0}=0, T=1$ [год], вектор початкового стану системи (8) приймався рівним $x^{0}=\left(x_{1}^{0}, x_{2}^{0}, x_{3}^{0}\right)^{T}=(286,17,568)^{T}$ [мг/л].

Використовувався метод повного перебору 3 рівномірним кроком для розв'язання завдання мінімізації критерію:

$$
I_{p}(\lambda, \mu)=\min _{k_{P}, k_{I}, k_{D}} J_{p}\left(k_{P}, k_{I}, k_{D}, \lambda, \mu\right)
$$

відносно параметрів $\lambda$ и $\mu$. Результати оптимізації методом повного перебору критерія (18) представлені в таблиці.

Таблиия. Оптимальні налаштування дробового $P I^{\lambda} D^{\mu}$ та класичного PID -регуляторів

\begin{tabular}{|c|c|c|c|c|c|c|}
\hline$p$ & $\lambda$ & $\mu$ & $k_{P}$ & $k_{I}$ & $k_{D}$ & $I_{p}(\lambda, \mu)$ \\
\hline 1 & 1 & 1 & $-0,1381$ & $-3,3019$ & $-0,0016$ & 0,0963 \\
\hline 1 & 0,9750 & 0,750 & $-0,2231$ & 0,0072 & $-1,0847 \cdot 10^{-5}$ & 0,0854 \\
\hline 2 & 1 & 1 & $-0,1294$ & $-3,6445$ & $-0,0015$ & 0,1184 \\
\hline 2 & 0,9875 & 0,600 & $-0,2234$ & 0,0068 & $-3,1249 \cdot 10^{-6}$ & 0,0855 \\
\hline
\end{tabular}


$\mathrm{У}$ шпальтах $\lambda$ и $\mu$ наведені порядки похідних та інтегралів дробових регуляторів, в шпальтах $k_{P}, k_{I}, k_{D}$ - оптимальні налаштування цих регуляторів, в останньому стовпчику - мінімальне значення критерію (18). Тут же для порівняння наведені результати оптимізації для класичного $P I D$-регулятора при $\lambda=1$ i $\mu=1$.

Результати показують, що значення цільової функції $I_{p}(\lambda, \mu)(p=1, p=2)$ при оптимальному дробовому $P I^{\lambda} D^{\mu}$-регуляторі менші, ніж при класичному PID-регуляторі.

Для дослідження поверхні критерію якості $I_{p}(\lambda, \mu)$ на рис. 3 зображений графік залежності цього критерію від порядків дробових похідних ( $\mu$ ) та інтегралів $(\lambda)$, які використовуються в дробовому $P I^{\lambda} D^{\mu}$-законі регулювання (15).

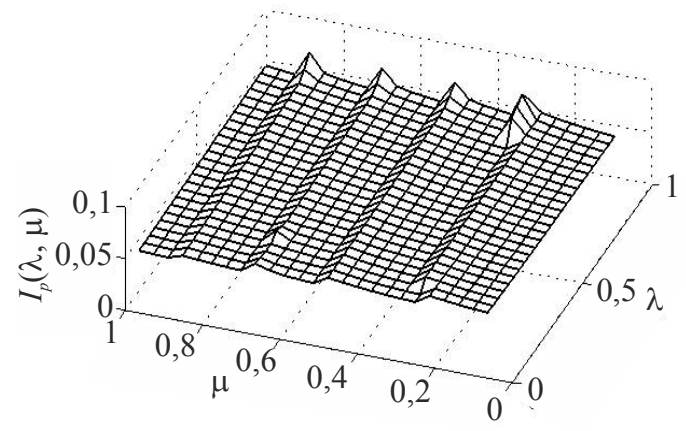

Рис. 3. Графік поверхні функції мети $I_{p}(\lambda, \mu)$

Результати були отримані за допомогою пакета Toolbox Optimization системи MATLAB. На рис. 4 представлені графіки оптимальних функцій керування (швидкості розведення потоку рідини) системи біологічної очистки води при класичному $P I D$ - і $P I^{\lambda} D^{\mu}$-дробових регуляторах (15).

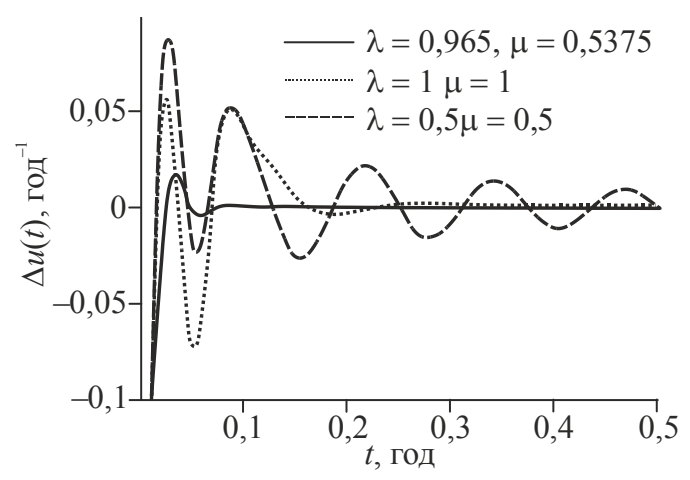

Рис. 4. Динаміка оптимальних дробових $P^{\lambda} D^{\mu}$-регуляторів

(швидкість розведення потоку рідини) і класичного PID-регулятора $(\lambda=1, \mu=1)$

На рис. 5 представлені графіки відповідних оптимальних перехідних процесів (зміни концентрації субстрату) цієї системи за критерієм $J_{2}\left(k_{P}, k_{I}, k_{D}, \lambda, \mu\right)$. 


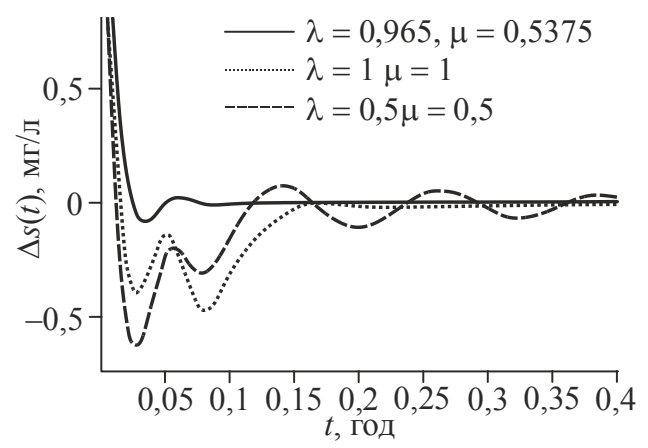

\section{Рис. 5. Оптимальні перехідні процеси зміни концентрації субстрату} при різних дробових $P I^{\lambda} D^{\mu}$ - і класичному $P I D$-регуляторах

Порівняльний аналіз динаміки перехідних процесів показує більш високу швидкість і якість загасання при оптимальному дробовому $P I^{\lambda} D^{\mu}$-регуляторі $(\lambda=0,965, \mu=0,5375)$ порівняно з оптимальним класичним $P I D$-регулятором $(\lambda=1, \mu=1)$. Видно, що оптимальні дробові регулятори 3 точним налаштуванням параметрів $\lambda$ (порядок дробового інтеграла) і $\mu$ (порядок дробової похідної) $є$ більш ефективними порівняно з класичним PID-регулятором.

\section{Висновки}

Ступінь ефективності дробових регуляторів і причини високої чутливості критерію оптимальності і перехідних процесів щодо порядків дробових похідних та інтегралів вимагають подальших досліджень.

\section{Література}

1. Авсиевич А.В. Моделирование систем автоматического управления с дробным ПИДрегулятором [Текст] / А.В. Авсиевич, В.В. Авсиевич // Вестник Самарского государственного технического университета, сер. техническое науки. — 2010. — № 1(26). - С. 6-59.

2. Бутковский А.Г. Дробное интегро-дифференциальное исчисление и его приложения в теории управления. II. Дробные динамические системы: моделирование и аппаратная реализация [Текст] / А.Г. Бутковский, С.С. Постнов, Е.А. Постнова // Автоматика и телемеханика. - 2013. - № 5. - С. 3-34.

3. Васильев B.B. Дробное исчисление и аппроксимационные методы в моделировании динамических систем. [Текст] / В.В. Васильев, Л.А. Симак. - Киев, НАН Украины, 2008. - $256 \mathrm{c}$.

4. Нахущев А.М. Дробное исчисление и его применение [Текст] / А.М. Нахушев // Москва : Физматлит, 2003. - $272 \mathrm{c.}$

5. Самко С.Г. Интегралы и производные дробного порядка и некоторые их приложения [Текст] / С.Г. Самко, А.А. Килбас, О.И. Маричев // Наука и техника. — Минск, 1987. —688 с.

6. Учайкин В.В. Метод дробных производных [Текст] / В.В. Учайкин // Ульяновск : Артишок, 2008. - $512 \mathrm{c}$.

7. Podlubny I. Fractional-order systems and PID controllers. IEEE Transactions on Automatic Control, 1999, 44: 208-214.

8. Podlubny I. Fractional Differential Equations / Mathematics in Sciences and Engineering, Vol. 198. - Academic Press, 1999. — 340 p.

9. Vinagre B.M., Petras I., Podlubny I., Chen Y.Q. Using fractional order adjustment rules and fractional order reference models in model-reference adaptive control. Nonlinear Dyn. 29(1-4), 269-279 (2002). 